\title{
VARIABILITY OF MORPHO-BIOLOGICAL TRAITS UNDER THE INFLUENCE OF LOW-FREQUENCY ELECTROMAGNETIC FIELDS ON VEGETATIVE ORGANS OF COTTON
}

\author{
Z.Y.Ibragimova ${ }^{1}$, A.A.Bekmukhamedov ${ }^{2}$, K.S.Davranov ${ }^{3}$, \\ I.G.Amanturdiev ${ }^{4}$ \\ ${ }^{1,2,3,4}$ National University of Uzbekistan named after Mirzo Ulugbek, str. University 4, 100174, \\ Tashkent, Uzbekistan.
}

Article DOI: https://doi.org/10.36713/epra8731

DOI No: 10.36713/epra8731

\begin{abstract}
In this article presents the obtained data on research the effect of low-frequency electromagnetic fields on the vegetative organs of cotton in conditions of normal and insufficient water regime. On the basis of the obtained results was revealed that the treatment of the vegetative organs of cotton with EMF will accelerate the growthdevelopment, ripeness and resistance to water deficiency.

KEY WORDS: cotton, processing, vegetative organs, low-frequency electromagnetic fields, water supply, plant height, between nodes, cotton boll.
\end{abstract}

\section{INTRODUCTION}

As you know, stress (hardening) increases other resistance to various harmful environmental factors. In this case, different data use different sources of electromagnetic fields: permanent magnets, sinusoidal fields of industrial frequencies of 50 hertz and other frequencies, pulse fields with different characteristics [1-2]. In addition, the effect of electromagnetic fields at other stages of plant development has practically not been studied, and the effect of various stress factors, for example, salinity or lack of water, has been poorly studied [3-4]. In the textbook "Electrotechnology" [5], it is recommended to carry out pre-sowing treatment of seed treatment with EMF, provided that they are not of high quality or that the growing environment does not correspond to the requirements of the genotype. Under optimal modes of electrical stimulation, the sowing qualities of seeds (germination energy, germination) improve, plant growth is accelerated, resistance to unfavorable environmental factors increases, which can result in an increase in yield by $5-20 \%$. Moreover, the probability of a positive effect depends on many factors and ranges from 0.50 to 0.75 . Such low reproducibility is in many cases the complexity and high cost of seed treatment plants. Despite these problems, it forces researchers to continue research in this direction. The stimulation of plants by EMF at the stages of vegetative development has been little studied, although there are a lot of works on the acting artificial EMF on living organisms in general and plants in particular, however, the mechanisms of this influence are hypotheses that need to be confirmed [6-7].

\section{MATERIALS AND METHODS}

The research material was the lines of the genetic collection of cotton of the species G.hirsutum L. L-452, L-4112 and the economic varieties Sultan, Ibrat. Field experiments on the experimental field of the NUUz botanical garden. The lines and varieties were sown in two plots, which were carried out in two background regimes - the regime of optimal water supply and (70-72\% of soil moisture content (WT, irrigation 1: 2: 1) and the mode of insufficient water supply (48-50\% WT, irrigation) 1: 1: 0). In each of the two background sources, each cultivar and line was planted in different rows with 25 plants 


\section{EPRA International Journal of Research and Development (IJRD)}

in a row, i.e. 75 plants per cultivar and line according to the sowing scheme $90 \times 20 \times 1$. During the flowering period for 10 days, the vegetative organs were treated with EMF and electric wires at frequencies of $4 \mathrm{~Hz}$.

\section{RESULTS AND DISCUSES}

The obtained values are presented in tables 1 and 2, which show the average values and differences between the plants of the experimental and control variants in the height of the main stem and the number between the nodes in the periods of flowering and ripening.

Significant differences and superiority of the experimental plants over the control plants during the flowering period were observed among the plants of the Ibrat variety $(\mathrm{K}-57.5 \pm 2.11 \mathrm{~cm}$; O-67.4 \pm 1.91 $\mathrm{cm}$; P-9.9) and in the line L $-452(\mathrm{~K}-71.2 \pm 1.96 \mathrm{~cm}$; O-73.3 $\pm 1.87 \mathrm{~cm}$; P-2.1), L-4112 (K-80.3 $\pm 2.19 \mathrm{~cm}$;
O- $81.3 \pm 2.14 \mathrm{~cm}$; P-1.0) under conditions of normal water supply, and under conditions of water deficiency in the Sultan variety $(\mathrm{K}-56.3 \pm 1.86 \mathrm{~cm}$; O-62.6 $\pm 2.15 \mathrm{~cm} ; \mathrm{R}-6.3)$ and in lines L-4112 (K$55.1 \pm 2.05 \mathrm{~cm} ;$ O-65.2 $\pm 1.96 \mathrm{~cm} ; \mathrm{R}-10.1), \mathrm{L}-452$ $(\mathrm{K}-54,1 \pm 1.91 \mathrm{~cm} ; \mathrm{O}-57.0 \pm 2.04 \mathrm{~cm} ; \mathrm{P}-2.9)$ according to the growth of the main stem. In terms of the number between nodes in the normal mode of water supply, the superiority of experimental plants over control observations in the Sultan variety (K$18.6 \pm 0.29 ; \mathrm{O}-19.1 \pm 0.33)$ and in the L-4112 line $(\mathrm{K}-18.1 \pm 0.34 ;$ O-18.6 \pm 0.31), L-452 (K-17.1 \pm $0.30 ;$ O-17.8 \pm 0.29$)$, and in the mode of water deficiency in the Sultan variety $(\mathrm{K}-17.3 \pm 0.27$; O$17.8 \pm 0.29$ and in lines L-4112 (K-15.2 \pm 0.33 ; O$15.9 \pm 0.32)$. were observed in the variety Ibrat (Table 1).

Tab. 1. Indicators of growth and the number of internodes under the influence of EMF on the vegetative organs of plants, varieties and lines during the flowering period

\begin{tabular}{|c|c|c|c|c|c|c|}
\hline \multirow{3}{*}{ Materials } & \multicolumn{6}{|c|}{ Main stem height $M \pm m(s m)$} \\
\hline & \multicolumn{3}{|c|}{ Normal mode } & \multicolumn{3}{|c|}{ Water deficient mode } \\
\hline & $\mathrm{K}$ & $\mathrm{O}$ & $\mathrm{P}$ & $\mathrm{K}$ & $\mathrm{O}$ & $\mathrm{P}$ \\
\hline Sultan & $71,4 \pm 1,67$ & $71,6 \pm 2,31$ & 0,3 & $56,3 \pm 1,86$ & $62,6 \pm 2,15$ & 6,3 \\
\hline Ibrat & $57,5 \pm 2,11$ & $67,4 \pm 1,91$ & 9,9 & $47,8 \pm 1,94$ & $48,2 \pm 1,89$ & 0,4 \\
\hline L-4112 & $80,3 \pm 2,19$ & $81,3 \pm 2,14$ & 1,0 & $55,1 \pm 2,05$ & $65,2 \pm 1,96$ & 10,1 \\
\hline L-452 & $71,2 \pm 1,96$ & $73,3 \pm 1,87$ & 2,1 & $54,1 \pm 1,91$ & $57,0 \pm 2,04$ & 2,9 \\
\hline \multicolumn{7}{|c|}{ Number between nodes $\mathrm{M} \pm \mathbf{m}(\mathrm{pc})$} \\
\hline \multirow{2}{*}{ Materials } & \multicolumn{3}{|c|}{ Normal mode } & \multicolumn{3}{|c|}{ Water deficient mode } \\
\hline & $\mathrm{K}$ & $\mathrm{O}$ & $\mathrm{P}$ & $\mathrm{K}$ & $\mathrm{O}$ & $\mathrm{P}$ \\
\hline Sultan & $18,6 \pm 0,29$ & $19,1 \pm 0,33$ & 0,5 & $17,3 \pm 0,27$ & $17,8 \pm 0,29$ & 0,5 \\
\hline Ibrat & $16,5 \pm 0,31$ & $16,7 \pm 0,35$ & $-0,2$ & $15,8 \pm 0,32$ & $15,1 \pm 0,27$ & $-0,7$ \\
\hline L-4112 & $18,1 \pm 0,34$ & $18,6 \pm 0,31$ & 0,5 & $15,2 \pm 0,33$ & $15,9 \pm 0,32$ & 0,7 \\
\hline L-452 & $17,1 \pm 0,30$ & $17,8 \pm 0,29$ & 0,7 & $14,7 \pm 0,31$ & $14,8 \pm 0,34$ & 0,1 \\
\hline
\end{tabular}

For note: $K$-control, $O$-experience, $P$-difference.

By the height of the main stem during the ripening period, the following results were obtained: in the mode of normal water supply, the Ibrat variety $(\mathrm{K}-72.3 \pm 2.11 \mathrm{~cm} ; \mathrm{O}-77.9 \pm 2.11 \mathrm{~cm}, \mathrm{P}-2.9)$, variety Sultan (K-81.2 $\pm 2.17 \mathrm{~cm}$; O-84.1 $\pm 1.87 \mathrm{~cm}, \mathrm{R}-5.6)$, line L-452 (K-93.4 $\pm 2.11 \mathrm{~cm}$. ; O-95.7 $\pm 1.96 \mathrm{~cm}, \mathrm{P}-$ 1.6) and line L-4112 (K-91.7 $\pm 2.07 \mathrm{~cm}$; O-93.3 \pm $1.96 \mathrm{~cm}, \mathrm{P}-2.3)$, and in the mode of insufficient water supply, line L-4112 (K-59.8 $\pm 2.15 \mathrm{~cm}$; O-68.4 $\pm 2.23 \mathrm{~cm}, \mathrm{R}-8.6)$, variety Sultan $(\mathrm{K}-61.4 \pm 2.14 \mathrm{~cm}$; O-68.5 $\pm 2.15 \mathrm{~cm}, \mathrm{R}-7.1)$, line L-452 (K-57.3 \pm 1.95 $\mathrm{cm}$; O-60, $1 \pm 1.94 \mathrm{~cm}, \mathrm{P}-2.1)$ and variety Ibrat $(\mathrm{K}-$ $52.9 \pm 2.04 \mathrm{~cm} ; \mathrm{O}-54.1 \pm 2.11 \mathrm{~cm}, \mathrm{P}-1.2)$. In terms of the number between the nodes in both modes of water supply (normal and water-deficiency), the superiority of the experimental plants over the control plants was observed in the Sultan variety and in the L-4112, L-452 lines (Table 2). Variety Ibrat, responding less to EMF in both water supply conditions, on the contrary, the control plants outperformed the experimental plants (normal mode P-0.4; water-deficient mode P-0.3). 


\section{EPRA International Journal of Research and Development (IJRD)}

Volume: 6 | Issue: 10 | October 2021

- Peer Reviewed Journal

Tab. 2. Indicators of growth and the number of internodes under the influence of EMF on the vegetative organs of plants of varieties and lines during ripening

\begin{tabular}{|c|c|c|c|c|c|c|}
\hline \multirow{3}{*}{ Materials } & \multicolumn{6}{|c|}{ Main stem height $M \pm m(s m)$} \\
\hline & \multicolumn{3}{|c|}{ Normal mode } & \multicolumn{3}{|c|}{ Water deficient mode } \\
\hline & $\mathrm{K}$ & $\mathrm{O}$ & $P$ & $\mathrm{~K}$ & $\mathrm{O}$ & $\mathrm{P}$ \\
\hline Sultan & $81,2 \pm 2,17$ & $84,1 \pm 1,87$ & 2,9 & $61,4 \pm 2,14$ & $68,5 \pm 2,03$ & 7,1 \\
\hline Ibrat & $72,3 \pm 2,11$ & $77,9 \pm 2,21$ & 5,6 & $52,9 \pm 2,04$ & $54,1 \pm 2,11$ & 1,2 \\
\hline L-4112 & $91,7 \pm 2,07$ & $93,3 \pm 1,96$ & 1,6 & $59,8 \pm 2,15$ & $68,4 \pm 2,23$ & 8,6 \\
\hline L-452 & $93,4 \pm 1,96$ & $95,7 \pm 1,91$ & 2,3 & $57,3 \pm 1,95$ & $60,1 \pm 1,94$ & 2,8 \\
\hline \multicolumn{7}{|c|}{ Number between nodes $M \pm m$ (pc) } \\
\hline \multirow{2}{*}{ Materials } & \multicolumn{3}{|c|}{ Normal mode } & \multicolumn{3}{|c|}{ Water deficient mode } \\
\hline & $\mathrm{K}$ & $\mathrm{O}$ & $\mathrm{P}$ & $\mathrm{K}$ & $\mathrm{O}$ & $\mathrm{P}$ \\
\hline Sultan & $19,2 \pm 0,33$ & $19,9 \pm 0,28$ & 0,7 & $17,5 \pm 0,31$ & $17,8 \pm 0,29$ & 0,3 \\
\hline Ibrat & $17,7 \pm 0,39$ & $17,3 \pm 0,31$ & $-0,4$ & $16,1 \pm 0,27$ & $15,8 \pm 0,34$ & $-0,3$ \\
\hline L-4112 & $19,2 \pm 0,31$ & $19,8 \pm 0,26$ & 0,6 & $16,0 \pm 0,30$ & $16,9 \pm 0,37$ & 0,9 \\
\hline L-452 & $19,4 \pm 0,28$ & $20,3 \pm 0,32$ & 0,9 & $15,4 \pm 0,29$ & $15,9 \pm 0,33$ & 0,5 \\
\hline
\end{tabular}

For note: $K$-control, $O$-experience, $P$-difference.

On table 3 shows the results of the analysis of the number of sympodial branches and the number of bolls during the ripening period. As can be seen from the data in the table, the superiority of experimental plants over control plants under conditions of normal water supply in the following order, line L-452 (K-13.4 \pm 0.31 pcs.; O-14.3 \pm 0.35 pcs.; R- 0.9) and L-4112 (K-13.1 \pm 0.29 units; O-13.8 \pm 0.36 units; $R-0.7)$, then Sultan varieties (K-13.3 \pm 0.29 pcs.; O-13.9 \pm 0.37 pcs.; R-0.6) and Ibrat (K$12.3 \pm 0.32$ pcs., $\mathrm{O}-12.7 \pm 0.41$ pcs. , P-0.4). In the mode of water deficiency, in addition to variety Ibrat, a clear superiority of experimental plants over control plants was observed in lines L-4112 (R-0.9 pcs.), L-
452 (R-0.6 pcs.) And in variety Sultan (F- 0.4 pcs.). According to the number of bolls, the following results were obtained: under normal water conditions - variety Ibrat K-6.4 \pm 0.39; O-10.1 \pm 0.48 (R-3.7 pcs.), Line L-4112, line K-11.7 \pm 0.43 ; O-12.9 \pm 0.46 (P-1.2 pcs.), Variety Sultan K-9.7 \pm 0.47 ; O-10.6 \pm 0.51 (P-0.9 pcs.) And line L-452 K-10.4 \pm 0.38 ; O$11.2 \pm 0.44 ; \mathrm{P}-0.8$ pcs.), And in conditions of water shortage, at the beginning the Sultan K-5.5 \pm 0.43 variety; O-8.2 \pm 0.54 (P-2.9 pcs.), Then the variety Ibrat K-4.2 \pm 0.47 ; O-6.3 \pm 0.38 (P-2.1 pcs.) And lines L-4112 K-6.3 $\pm 0.50 ; 0-8.40 \pm 0.46(\mathrm{R}-2.1$ pcs.), L-452 K-4.9 \pm 0.41 ; O-5.3 \pm 0.57 ; P-0.4 pcs. (Table 3).

Tab. 3. Indicators of the number of sympodial branches and bolls under the influence of EMF on the vegetative organs of plants of varieties and lines during ripening

\begin{tabular}{|c|c|c|c|c|c|c|}
\hline \multirow{3}{*}{ Materials } & \multicolumn{6}{|c|}{ number of sympodial branches $\mathrm{M} \pm \mathrm{m}(\mathrm{pc})$} \\
\hline & \multicolumn{3}{|c|}{ Normal mode } & \multicolumn{3}{|c|}{ Water deficient mode } \\
\hline & K & $\mathrm{O}$ & $\mathrm{P}$ & K & $\mathrm{O}$ & $\mathrm{P}$ \\
\hline Sultan & $13,3 \pm 0,34$ & $13,9 \pm 0,37$ & 0,6 & $11,1 \pm 0,28$ & $11,5 \pm 0,33$ & 0,4 \\
\hline Ibrat & $12,3 \pm 0,32$ & $12,7 \pm 0,41$ & 0,4 & $10,4 \pm 0,34$ & $10,2 \pm 0,31$ & $-0,2$ \\
\hline L-4112 & $13,1 \pm 0,29$ & $13,8 \pm 0,36$ & 0,7 & $10,7 \pm 0,37$ & $11,6 \pm 0,28$ & 0,9 \\
\hline L-452 & $13,4 \pm 0,31$ & $14,3 \pm 0,35$ & 0,9 & $10,5 \pm 0,32$ & $11,1 \pm 0,34$ & 0,6 \\
\hline \multicolumn{7}{|c|}{ number of cotton bolls $\quad M \pm m(p c)$} \\
\hline \multirow{2}{*}{ Materials } & \multicolumn{3}{|c|}{ Normal mode } & \multicolumn{3}{|c|}{ Water deficient mode } \\
\hline & $\mathrm{K}$ & $\mathrm{O}$ & $\mathrm{P}$ & K & $\mathrm{O}$ & $\mathrm{P}$ \\
\hline Sultan & $9,7 \pm 0,47$ & $10,6 \pm 0,51$ & 0,9 & $5,5 \pm 0,43$ & $8,2 \pm 0,54$ & 2,9 \\
\hline Ibrat & $6,4 \pm 0,39$ & $10,1 \pm 0,48$ & 3,7 & $4,2 \pm 0,47$ & $6,3 \pm 0,38$ & 2,1 \\
\hline L-4112 & $11,7 \pm 0,53$ & $12,9 \pm 0,46$ & 1,2 & $6,3 \pm 0,50$ & $8,4 \pm 0,46$ & 2,1 \\
\hline L-452 & $10,4 \pm 0,38$ & $11,2 \pm 0,44$ & 0,8 & $4,9 \pm 0,41$ & $5,3 \pm 0,57$ & 0,4 \\
\hline
\end{tabular}

For note: $K$-control, $O$-experience, $P$-difference. 


\section{EPRA International Journal of Research and Development (IJRD) \\ Volume: 6 | Issue: 10 | October 2021 \\ - Peer Reviewed Journal}

\section{CONCLUSIONS}

Thus, the following can be noted: - the effect of low-frequency EMF on the vegetative organs of plants in the varieties Sultan, Ibrat and in the line L4112, L-452, dynamic growth was observed along the height of the main stem both under normal water conditions and under water conditions. deficiency, superiority of experimental plants over control plants;

- in terms of the number between nodes and sympodial branches, the superiority of the experimental plant variants over the control plant variant was observed in the Sultan variety and in the L-4112, L-452 lines, such a change in the studied traits was not observed in the Ibrat variety;

- in terms of the number of bolls, significant differences in the condition of the normal water supply regime were observed in the Ibrat variety and in the L-4112 lines, and in the condition of insufficient water supply in the Sultan, Ibrat and L4112 varieties.

\section{REFERENCES}

1. Medvedev S.S. Plant physiology // Textbook. SP BHV-Petersburg. 2012.- 512 p.

2. Field V.V. Plant physiology // Textbook. M .: Higher school, 1989.- 464 p.

3. Tonkikh A.K., Makhmurova D.M., Radzhabova G.G. Presowing electromagnetic hardening of cotton seeds increases the salt tolerance of crops. // Bulletin of NUUz. Special issue. 2011. - p. 7879.

4. Khatamov M.M., Akhmedzhanov I.G., Kurbanbaev I.D. et al. Induction of cotton resistance to wilt by a low-frequency electromagnetic field. // Bulletin of NUUz. 2013. No. 4/2. - pp. 47-49.

5. Karasenko V.A., Hare Z.M., Baran A.N. and other Electrotechnology. // M .: Kolos, 1992. $304 \mathrm{p}$.

6. Bingi V.N. Magnetobiology. Experiments and Models. // M. Milta. 2020.- 592 p.

7. Bingi V.N. Principles of electromagnetic biophysics. // Fizmatlit. 2011.- 590 p. 